\title{
Radiology
}

\section{Mammographic Density Errors during Interpretation of Breast Examinations}

\author{
Tamara V. Pavlova, MD, $\mathrm{PhD}^{1,2}$; Aleksandr Yu. Vasilyev, $\mathrm{MD}, \mathrm{PhD}, \mathrm{ScD}^{1,3^{*}}$; \\ Ivan V. Buromsky, $\mathrm{MD}, \mathrm{PhD}, \mathrm{ScD}^{4}$ \\ ${ }^{1}$ Central Research Institute of Radiation Diagnostics \\ ${ }^{2}$ City Clinical Hospital named after V. M. Buyanov \\ ${ }^{3}$ Moscow State University of Medicine and Dentistry named after A. I. Evdokimov \\ ${ }^{4}$ Russian National Research Medical University named after N. I. Pirogov \\ Moscow, Russia
}

\begin{abstract}
Background: This article discusses errors that may occur when radiologists deal with mammographic density (MD) and present their performance analysis in Russia.

Methods and Results: The authors of this report have analyzed 24,485 mammographic reports for 20,000 female patients (aged 29-85 years) that were made in various healthcare facilities in the Russian Federation. In 249(1.7\%) mammographic exam reports, we observed a wrong MD interpretation.

Conclusion: Diagnostic errors during mammographic examination occur because the radiologists lack theoretical knowledge about MD. This lack, in turn, results in a decrease in the quality of medical care provided for female patients and an increase in the number of diagnostic iatrogeny. (International Journal of Biomedicine. 2020;10(4):378-381.)
\end{abstract}

Key Words: mammographic density $\bullet$ iatrogeny $\bullet$ error $\bullet$ breast cancer

\section{Abbreviations}

MD, mammographic density; BC, breast cancer.

\section{Introduction}

Despite the fact that medicine is constantly developing, and there are many scientific works devoted to the diagnosis and treatment of breast cancer (BC), the incidence and mortality rates of this disease are among the highest of all the cancer types. ${ }^{(1-3)}$ Like any other pathologic process, a $\mathrm{BC}$ has its own risk factors. Many scientists believe that mammographic density (MD) is the key BC predictor. ${ }^{(4-6)}$ Various sources state that according to the mammogram results, more than half of female patients under 50 have high MD values. ${ }^{(7)}$ It is worth mentioning that the mammograms that display a high and extreme MD are often hard to interpret. ${ }^{(8)}$ On the one hand,

"Corresponding author: Prof. Alexander Yu. Vasilyev, MD, PhD, ScD. Department of Radiology, Moscow State University of Medicine and Dentistry named after A. I. Evdokimov, Moscow, Russia.E-mail:auv62@mail.ru there is a risk of obtaining a false-negative result because the diagnostic accuracy of mammography decreases; on the other hand, a risk of a false-positive due to the tissue architecture superposition effect. ${ }^{(9,10)}$ That is why the MD values are vital for determining the risk of breast cancer development. They should be under control throughout a patient's life. ${ }^{(11)}$ The scientists have proposed both quantitative and qualitative approaches to assessing MD, but the American College of Radiology (ACR) has strongly recommended using the latter one since 2013. ${ }^{(12-14)}$ If MD is classified as " $C$ " or " $\mathrm{D}$," the female patients are strongly recommended to undergo supplementary screenings; in most cases, this is an ultrasound scan, no matter whether they have pathologic changes or not. ${ }^{(15)}$ However, due to certain subjectivity of classifications, there is some variability in mammographic pattern interpretation. This often results in miscategorization of MD and, consequently, in errors in further patient follow-up. 


\section{Materials and Methods}

The authors of this report have analyzed 24,485 mammographic reports for 20,000 female patients (aged 2985 years) that were made in various healthcare facilities in the Russian Federation in the period of 2008-2020, in order to assess the quality of work of Russian radiologists with regard to MD interpretation.

\section{Results and Discussion}

The MD category has been stated in 14,509(59.4\%) cases. In $9,916(40.6 \%)$ reports, there was no data about the MD category. If we speak about 14,509 cases, where the mammographic density has been stated, it is worth mentioning that in $6,645(45.8 \%)$ cases the radiologists resorted to the outdated method of MD detection, which is based on the calculation of the percentage ratio of fat and fibroglandular components (Wolfe, 2003). Since 2013, the ACR has been taking into account the fact that the pathologic area can disguise itself as dense structures of a breast. Besides, Roman numerals (I-IV) that used to denote the MD grades were replaced by letters (A, B, C, D). As the research data embraced the period of 2008-2020, we did not consider a percentage ratio method as a completely improper one. We have divided the mammographic reports into 2 groups, depending on the assessment systems for MD of breast tissue applied. The graph is shown in Fig. 1.

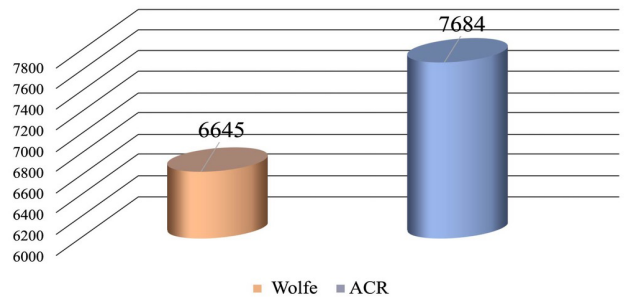

Fig. 1. The distribution of cases, depending on the employed method of evaluation and interpretation of $M D(n=14,509)$

In $249(1.7 \%)$ mammographic exam reports, we observed a wrong MD interpretation. The correlation between errors in $\mathrm{MD}$ detection and the total amount of categorized cases is shown in Fig.2.

249

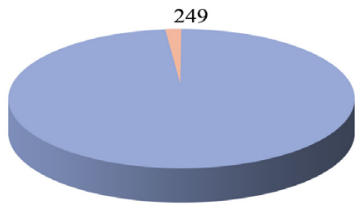

a

errors in mammographic density categorisation

Fig. 2. The error rate in MD of mammary gland tissue, if the density category is stated $(n=14,509)$.
Table 1 contains the cases of the wrong MD interpretations $(249=100 \%)$.

Table 1.

The distribution of the misassigned categories of MD $(n=249)$

\begin{tabular}{|c|c|c|}
\hline & \multicolumn{2}{|c|}{ MD according to radiologists' reports } \\
\hline Category & Abs. & $(\%)$ \\
\hline ACR BI-RADS A & 14 & 5.6 \\
\hline ACR BI-RADS B & 151 & 60.6 \\
\hline ACR BI-RADS C & 66 & 26.5 \\
\hline ACR BI-RADS D & 18 & 7.2 \\
\hline
\end{tabular}

We have divided them into the following categories:

1) $14(5.6 \%)$ cases were classified as ACR BI-RADS A, while mammograms have shown that there is a sufficient amount of fibroglandular tissue.

2) $151(60.6 \%)$ cases were miscategorized as ACR BIRADS B instead of A (n=104) or C (n=47) (Fig.3).

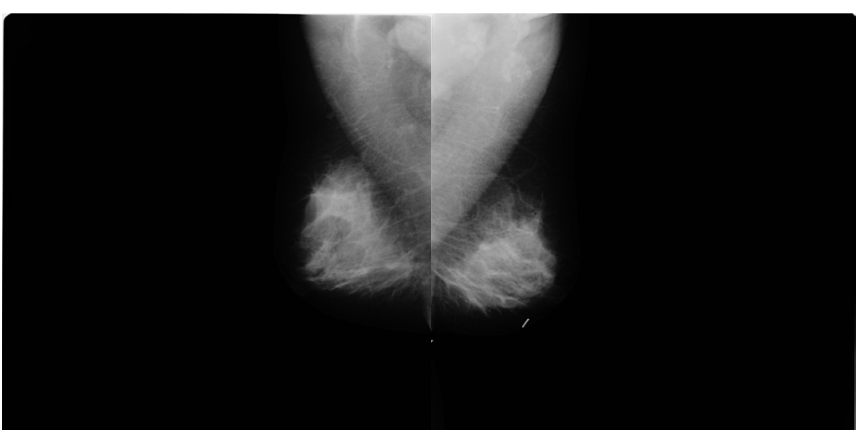

(a)

(b)

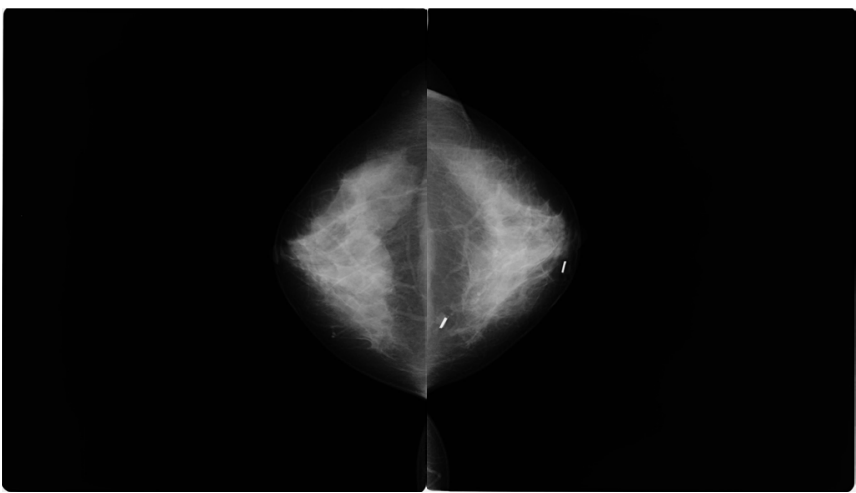

(c)

(d)

Fig. 3. A 49-year-old woman. Mammograms in 2 standard planes: a, $c$-mammograms of a right breast in inclined and straight planes, $b, d$-mammograms of a left breast in inclined and straight plane. In the radiological conclusion, $M D$ of breast tissue is identified as ACR BI-RADS B; the female patient is supposed to undergo a mammographic exam one more time in 2 years. The category is stated incorrectly, MD of breast tissue of this patient corresponds to ACR BI-RADS C. That means that she should make an ultrasound scan immediately. 
3) Heterogeneous MD (ACR BI-RADS C) was misinterpreted in $66(26.5 \%)$ cases, while the exams of 52 female patients had to be interpreted as ACR BI-RADS B (Fig. 4) and 14 as ACR BI-RADS D.

4) Errors with ACR BI-RADS D were quite rare. There were only $18(7.2 \%)$ reports with ACR BI-RADS D, while the breast did not entirely consist of fibro-glandular tissue. There were numerous heterogeneous areas of a dense structure (ACR-BI-RADS C).

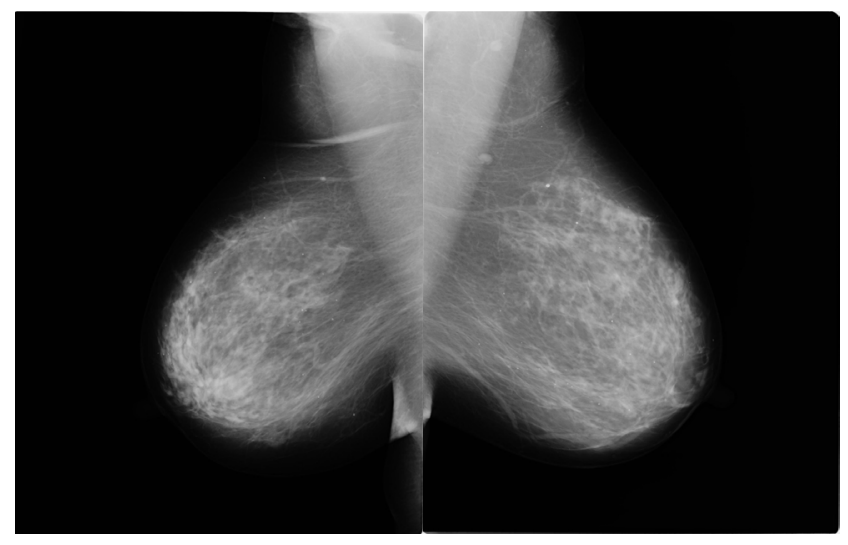

(a)

(b)

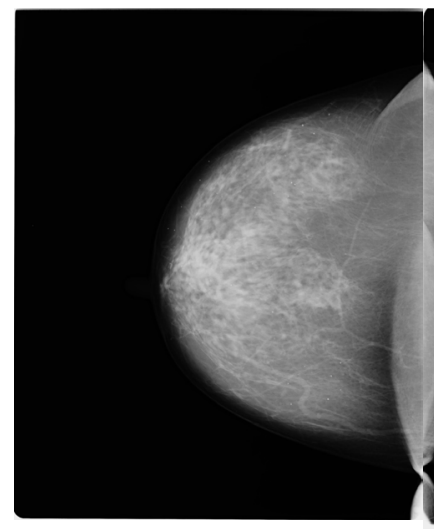

(c)

(d)

Fig. 4. A 53-year-old woman. Mammograms in 2 standard planes: a, c-mammograms of a right breast in inclined and straight planes; $b, d$-mammograms of a left breast in inclined and straight planes. In the radiological report, $M D$ of breast tissue is identified as ACR BI-RADS C; the radiologist has recommended to make an ultrasound scan. The category is stated incorrectly, MD of breast tissue of this patient corresponds to ACR BI-RADS B. That means that the patient has to undergo a routine and control mammographic exam with respect to her age.

After analyzing the results of the conducted research, we can conclude that Russian radiologists register MD in less than a half of all the mammographic exam reports. If we speak about cases, when ACR BI-RADS categories have been identified, the most crucial diagnostic errors were B miscategorizations, when actually there were heterogeneous dense structures, and incorrectly stated $\mathrm{C}$ category for breasts with sporadic areas of fibroglandular tissue. In the first case, the patients won't undergo an ultrasonic scan, which is obligatory and indicated for patients with high and extreme MD, and this can result in false-negative diagnostic results. In the second case, on the contrary, an ultrasonic scan will complicate a diagnostic path and may lead to stressful situations for the patients.

In conclusion, when radiologists fail to state the category of the $\mathrm{MD}$, or misidentify it, this often results in an increase in iatrogenic injuries of the breast, as well as in a decrease in the quality of medical care provided for patients that leads to late detection of malignant activity in mammary glands.

\section{Competing Interests} interests.

The authors declare that they have no competing

\section{References}

1. Ferlay J, Colombet M, Soerjomataram I, Mathers C, Parkin DM, Piñeros M, Znaor A, Bray F. Estimating the global cancer incidence and mortality in 2018: GLOBOCAN sources and methods. Int J Cancer. 2019 Apr 15;144(8):1941-1953. doi: 10.1002/ijc.31937.

2. Bray F, Ferlay J, Soerjomataram I, Siegel RL, Torre LA, Jemal A. Global cancer statistics 2018: GLOBOCAN estimates of incidence and mortality worldwide for 36 cancers in 185 countries. CA Cancer J Clin. 2018 Nov;68(6):394-424. doi: $10.3322 /$ caac. 21492 .

3. Torre LA, Siegel RL, Ward EM, Jemal A. Global Cancer Incidence and Mortality Rates and Trends--An Update. Cancer Epidemiol Biomarkers Prev. 2016 Jan;25(1):16-27. doi: 10.1158/1055-9965.

4. Labazanova PG, Rozhkova NI, Burdina II, Zapirova SB, Mazo ML, Mikushin SYu, Prokopenko SP, Jacobs OE. [Mammographic density and risk of breast cancer (a look at the history of studying the issue)]. Russian Electronic Journal of Radiology. 2020; 10(2):205-222. DOI:10.21569/22227415-2020-10-2-205-222.[Article in Russian].

5. Duffy SW, Morrish OWE, Allgood PC, Black R, Gillan MGC, Willsher P, Cooke J, Duncan KA, Michell MJ, Dobson HM, Maroni R, Lim YY, Purushothaman HN, Suaris T, Astley SM, Young KC, Tucker L, Gilbert FJ. Mammographic density and breast cancer risk in breast screening assessment cases and women with a family history of breast cancer. Eur J Cancer. 2018 Jan;88:48-56. doi: 10.1016/j.ejca.2017.10.022.

6. Nazari SS, Mukherjee P. An overview of mammographic density and its association with breast cancer. Breast Cancer. 2018 May;25(3):259-267. doi: 10.1007/s12282-018-0857-5.

7. Sprague BL, Gangnon RE, Burt V, Trentham-Dietz A, Hampton JM, Wellman RD, Kerlikowske K, Miglioretti DL. Prevalence of mammographically dense breasts in the United States. J Natl Cancer Inst. 2014 Sep 12;106(10):dju255. doi: 10.1093/jnci/dju255.

8. Bakker MF, de Lange SV, Pijnappel RM, Mann RM, Peeters PHM, Monninkhof EM, Emaus MJ, Loo CE, Bisschops RHC, Lobbes MBI, de Jong MDF, Duvivier KM, Veltman J, Karssemeijer N, de Koning HJ, van Diest PJ, Mali WPTM, van den Bosch MAAJ, Veldhuis WB, van Gils CH; DENSE Trial Study Group. Supplemental MRI Screening for Women with Extremely Dense Breast Tissue. N Engl J Med. 2019 Nov 
28;381(22):2091-2102. doi: 10.1056/NEJMoa1903986. 9. Nelson HD, O’Meara ES, Kerlikowske K, Balch S, Miglioretti D. Factors Associated With Rates of False-Positive and False-Negative Results From Digital Mammography Screening: An Analysis of Registry Data. Ann Intern Med. 2016 Feb 16;164(4):226-35. doi: 10.7326/M15-0971.

10. Wadhwa A, Sullivan JR, Gonyo MB. Missed Breast Cancer: What Can We Learn? Curr Probl Diagn Radiol. 2016 Nov-Dec;45(6):402-419. doi: 10.1067/j.cpradiol.2016.03.001. 11. Natesan R, Wiskin J, Lee S, Malik BH. Quantitative Assessment of Breast Density: Transmission Ultrasound is Comparable to Mammography with Tomosynthesis. Cancer Prev Res (Phila). 2019 Dec;12(12):871-876. doi: 10.1158/1940-6207.CAPR-19-0268.

12. Boyd NF, O’Sullivan B, Campbell JE, Fishell E, Simor I,
Cooke G, Germanson T. Mammographic signs as risk factors for breast cancer. Br J Cancer. 1982 Feb;45(2):185-93. doi: 10.1038/bjc. 1982.32 .

13. Wolfe JN. Risk for breast cancer development determined by mammographic parenchymal pattern. Cancer. 1976 May;37(5):2486-92. doi: $10.1002 / 1097-0142(197605) 37: 5<2486:$ : a id cncr2820370542>3.0.co;2-8.

14. Spak DA, Plaxco JS, Santiago L, Dryden MJ, Dogan BE. BI-RADS ${ }^{\circledR}$ fifth edition: A summary of changes. Diagn Interv Imaging. 2017 Mar;98(3):179-190. doi: 10.1016/j. diii.2017.01.001.

15. D’Orsi CJ, Sickles EA, Mendelson EB, Morris EA. ACR BI-RADS Atlas: Breast Imaging Re-porting and Data System. American College of Radiology, Reston, VA, USA; 2013. 